International Journal of Advanced Chemistry, $9(1)(2021) 20-24$
International Journal of Advanced Chemistry
SPC
Website: www.sciencepubco.com/index.php/IJET
Research paper

\title{
Comparative phytochemical screening and antioxidant activity of lemon grass and sweet wormwood leaves extract
}

\author{
Murtala R. ${ }^{1}$, Alhassan S. I. ${ }^{1}$, Rasheed H. I. ${ }^{2}$, Dalhatu S. N. ${ }^{3}$, Bala S. S. ${ }^{1}$, Idris S. A. ${ }^{4}$, Anyanaso D. C. ${ }^{3}$ \\ ${ }^{1}$ Kano University of Science and Technology, Wudil, Kano Nigeria \\ ${ }^{2}$ Bayero University Kano, Nigeria \\ ${ }^{3}$ Abubakar Tafawa Balewa University Bauchi, Nigeria \\ ${ }^{4}$ Federal Polytechnic Offa, Kwara Nigeria \\ *Corresponding author E-mail: reedwanu@gmail.com
}

\begin{abstract}
Sweet wormwood (Artemisia annua) and lemongrass (Cymbopogon citratus) leaves were extracted with methanol, evaporated to dryness and processed for antioxidant activity and phytochemical screening. Phosphomolybdenum Reagent was prepared using standard procedure. An aliquot mixture of $2 \mathrm{~mL}$ of extract solution $(1000 \mu \mathrm{g} / \mathrm{mL}, 500 \mu \mathrm{g} / \mathrm{mL}, 250 \mu \mathrm{g} / \mathrm{mL}, 125 \mu \mathrm{g} / \mathrm{mL}, 62.5 \mu \mathrm{g} / \mathrm{mL}, 31.25 \mu \mathrm{g} / \mathrm{mL}$ and $15.625 \mu \mathrm{g} / \mathrm{mL}$ ) was mixed with $1.8 \mathrm{~mL}$ of reagent solution. The samples tubes were incubated at $95^{\circ} \mathrm{C}$ for 90 minutes. The absorbance of the aqueous solutions was measured at $695 \mathrm{~nm}$ against blank. Antioxidant activities of the plants extract were also measured in terms of hydrogen donating radical scavenging ability using the stable DPPH method. Absorbance was recorded at $517 \mathrm{~nm}$ against blank using a UV-Vis spectrophotometer. The result of in vitro antioxidant potential of the methanolic leaves extract showed more increase in concentration the higher the absorbance. Qualitative Phytochemical Analysis of Lemon Grass and Sweet wormwood shows the presence of phytochemical in lemongrass and sweet wormwood such as flavonoid, tannin, steroid, saponins and cardiac glycoside.
\end{abstract}

Keywords: Antioxidant; Free Radical; Phytochemical; Lemon Grass; Sweet Wormwood.

\section{Introduction}

Phytochemicals are bioactive compounds found in vegetables, fruits, cereal grains, and plant based beverages such as tea and wine. Phytochemical consumption is associated with a decrease in risk of several types of chronic diseases due to their impact to antioxidant and free radical scavenging effects (Yu-Jie et al., 2013). Free radicals are the natural by-product of biochemical processes, that is metabolism in a cell, and when build up, they harm the cells of the body if not scavenged. Yet free radical is essential to life, the body's ability to turn oxygen and food depends on a chain of free radicals. They are also crucial part of immune system, floating through the veins and attacking foreign invaders (László et al., 2005). Cancer and atherosclerosis, two major causes of death, are salient "free radical" diseases. Cancer initiation and promotion is associated with chromosomal defects and oncogenes activation. It is possible that endogenous free radical reactions, like those initiated by ionizing radiation, may result in tumor formation (Lobo et al., 2010). DNA is the major target of free radical damage. The type of damage is many and include strand breaks, various forms of base damages can result in mutations that are heritable change in DNA that can yield cancer in somatic cells or fetal malformations in the germ cells, the role of free radicals with tumor suppressor gene and oncogenes suggest their involvement in developing different human cancer (Miral and Pawel, 2012). Antioxidants are used to counterbalance the effect of free radicals. An antioxidant is a stable molecule which donates an electron to a charged free radical and terminates the chain reaction before vital molecules are damaged, Free radical scavenging property of antioxidants delays or inhibits cellular damage (Satish and Dilipkumar, 2015). Antioxidants are in high need, as they help in lowering ageing signs. Therefore the use of plant products has been increasing every day to lower side effects (Lobo et al., 2010). In recent years, antioxidants have gained a lot of importance due to their potentials as prophylactic and therapeutic agents in many diseases. Traditionally, herbal medicines with antioxidant properties have been used for various purposes, and epidemiological data also point to widespread acceptance and use of these agents (Michael, 2012). Antioxidants can be classified into two major groups; enzymatic and non-enzymatic antioxidants. Some of these antioxidants are endogenously produced, including enzymes, low molecular weight molecules, and enzyme cofactors. Many non-enzymatic antioxidants are obtained from dietary sources. Dietary antioxidants can be classified into various classes, of which polyphenols is the largest class. Polyphenols consist of phenolic acids and flavonoids. The other classes of dietary antioxidants include vitamins, carotenoids, organosulfural compounds, and minerals (Michael, 2012). The objective of this research is to determine and compare the phytochemicals content and the in vitro antioxidant properties of the leaf extract of lemongrass and sweet wormwood. 


\section{Methodology}

\subsection{Sample collection}

Sweet wormwood (Artemisia annua) and lemongrass (Cymbopogon citratus) were purchased from Wudil market, Wudil L.G.A Kano state. The leaves of the plants were taken, air-dried and pulverized via mortar and pestle into fine powder.

\subsection{Plant extraction}

The powdered form of lemongrass and sweet wormwood were measured $(100 \mathrm{~g})$ in two separate flasks and were prepared by soaking in $400 \mathrm{ml}$ of methanol each. The two mixtures were left to stand at room temperature for 48 hours and then filtered using Whitman filter paper No. 42 using vacuum pump. The alcoholic filtrates (methanol) were evaporated. All the samples were extracted that is, 50\% Methanol was evaporated to dryness and processed for antioxidant activity and phytochemical analysis (Azwanida, 2015).

\subsection{Reagents preparation}

\subsubsection{Phosphomolybdenum reagent preparation}

To prepare Phosphomolybdnate reagent solution, (0.6M sulphuric acid, $30 \mathrm{mM}$ sodium phosphate and $4 \mathrm{mM}$ ammonium molybdate). $3.33 \mathrm{ml}$ of sulphuric acid was diluted with $100 \mathrm{ml}$ of distilled water $\left(\mathrm{D} . \mathrm{H}_{2} \mathrm{O}\right)$, then followed by adding 0.4 grams of Sodium Phosphate and 0.5 grams of Ammonium Molybdate (Prieto et al., 1999).

\subsection{Antioxidant}

An aliquot mixture of $2 \mathrm{~mL}$ of extract solution $(1000 \mu \mathrm{g} / \mathrm{mL}, 500 \mu \mathrm{g} / \mathrm{mL}, 250 \mu \mathrm{g} / \mathrm{mL}, 125 \mu \mathrm{g} / \mathrm{mL}, 62.5 \mu \mathrm{g} / \mathrm{mL}, 31.25 \mu \mathrm{g} / \mathrm{mL}$ and $15.625 \mu \mathrm{g} / \mathrm{mL})$ was mixed with $1.8 \mathrm{~mL}$ of mixture reagent solution $(0.6 \mathrm{M}$ sulphuric acid, $30 \mathrm{mM}$ sodium phosphate and $4 \mathrm{mM}$ ammonium molybdate). The samples tubes were sealed and incubated in a boiling water bath at $95^{\circ} \mathrm{C}$ for 90 minutes. After incubation, the samples were cooled to room temperature, the absorbance of the aqueous solution of each was measured at $695 \mathrm{~nm}$ against blank. A typical blank contained $1 \mathrm{~mL}$ reagent solution and appropriate volume of same volume of the solvent used for the samples and it was incubated under the same conditions as the rest of the samples (Prieto et al., 1999).

\subsubsection{DPPH (1,1-diphenyl-2-picrylhydrazyl) free radical scavenging activity}

Antioxidant activity of sweet wormwood and lemongrass extract were measured in terms of hydrogen donating radical scavenging ability using the stable DPPH method. The reaction was monitored as a color change from purple to pale yellow. A quantity $0.1 \mathrm{ml}$ of sweet wormwood and lemongrass each extract was added to $0.2 \mathrm{ml}$ of $100 \mu \mathrm{M}$ DPPH solution in methanol and the reaction mixture was kept in the dark for $45 \mathrm{~min}$. Absorbance was recorded at $517 \mathrm{~nm}$ against blank using a UV-Vis spectrophotometer. Ascorbic acid was used as standard (Zhu et al., 2006). The radical scavenging activity on DPPH was expressed as,

Scavenging activity (inhibition) $\%=\left[100-\left\{\left(\mathrm{A}_{\mathrm{s}}-\mathrm{A}_{\mathrm{b}} / \mathrm{A}_{\mathrm{c}}\right)\right\}\right] \mathrm{X} 100$

Where; $A_{c}$ is the absorbance of control,

$\mathrm{A}_{\mathrm{s}}$ is the absorbance of sample extract or standard

$A_{b}$ is the absorbance of blank.

\subsection{Qualitative determination of some phytochemicals}

\subsubsection{Test for flavonoids}

Alkaline Reagent Test: Extracts were treated with few drops of $20 \%$ sodium hydroxide solution. Formation of intense yellow colour, which becomes colorless on addition of dilute acid, indicates the presence of flavonoids.

\subsubsection{Test for alkaloids}

Dragendroff's Test: Extracts were treated with few drops of Dragendroff's reagent. A reddish brown precipitate indicates the presence of alkaloids Wagener's Test: Extracts were treated with few drops of Wagner's reagent. A whitish precipitate indicates the presence of alkaloid.

\subsubsection{Test for steroid}

Liebermann-Burchard's test: To a portion of the extract, equal volume of acetic acid anhydride was added and mixed gently, $1 \mathrm{ml}$ of concentrated sulphuric acid was added down the side of the test tube to form a lower layer. A colour change was observed immediately and later indicates the presence of steroid. A blue or blue green indicates steroids.

\subsubsection{Test for cardiac glycoside}

Kella-killiani's test: A portion of the extract was dissolved in $1 \mathrm{ml}$ of glacial acetic acid containing traces of ferric chloride solution. This was then transferred into a dry test tube and $1 \mathrm{ml}$ of concentrated sulphuric acid was added down the side of the test tube to form a lower layer at the bottom. The mixture was observed carefully at the interphase for purple-brown ring, this indicates the presence of deoxy sugars and pale green colour in the upper acetic acid layer indicates the presence of cardiac glycosides. 


\subsubsection{Test for tannins}

Ferric Chloride test: To a portion of the extract, 3-5 drops of ferric chloride was added. A greenish black precipitate indicates presence of condensed tannins while hydrolysable tannins give a blue or brownish blue precipitate.

\subsubsection{Test for anthraquinones}

Bontrager's test: To portion of the extract in a dry test tube, $5 \mathrm{ml}$ of chloroform was added and shaken for at least 5 minutes. This was filtered and the filtrate shaken with equal volume of $10 \%$ ammonium solution, bright pink colour in the aqueous upper layer indicates the presence of free anthraquinones.

\subsubsection{Test for saponin frothing test}

About $10 \mathrm{ml}$ of distilled water was added to a portion of the extract and was shaken vigorously for 30 seconds. The test tube was allowed to stand in a vertical position and was observed for 30 minutes. A honeycomb forth persists for 10-15 minutes indicates presence of saponin.

\subsubsection{Test for carbohydrates molish's test}

To $1 \mathrm{ml}$ of the filtrate, $1 \mathrm{ml}$ of molish's reagent was added in a test tube, followed by $1 \mathrm{ml}$ of concentrated sulphuric acid down the test tube to form a layer. A reddish colour at the interfacial ring indicates the presence of carbohydrate.

\section{Result and discussion}

\subsection{Result}

The result of in vitro antioxidant potential (Phosphomolybdenum and DPPH free radical scavenging activity) of the methanolic leaves extracts of lemongrass and sweet wormwood are presented in Fig. 1and 2 respectively. Whereas, the qualitative phytochemical analysis of the above mentioned plant leaves extracts are presented in table 3.

Table 1: Phosphomolybdenum Assay

\begin{tabular}{llll}
\hline Concentration $(\mu \mathrm{g} / \mathrm{ml})$ & Absorbance for Ascorbic acid & Absorbance for lemongrass & Absorbance for Artemisia annua \\
\hline 1000 & 1.0641 & 16.93 & 13.2 \\
500 & 0.5997 & 18.81 & 14.66 \\
250 & 0.3678 & 15.39 & 13.2 \\
125 & 0.2311 & 12.09 & 9.429 \\
62.5 & 0.1380 & 13.03 & 11.01 \\
31.125 & 0.0999 & 8.465 & 6.6 \\
15.625 & 0.0698 & 1.693 & 1.32 \\
\hline
\end{tabular}

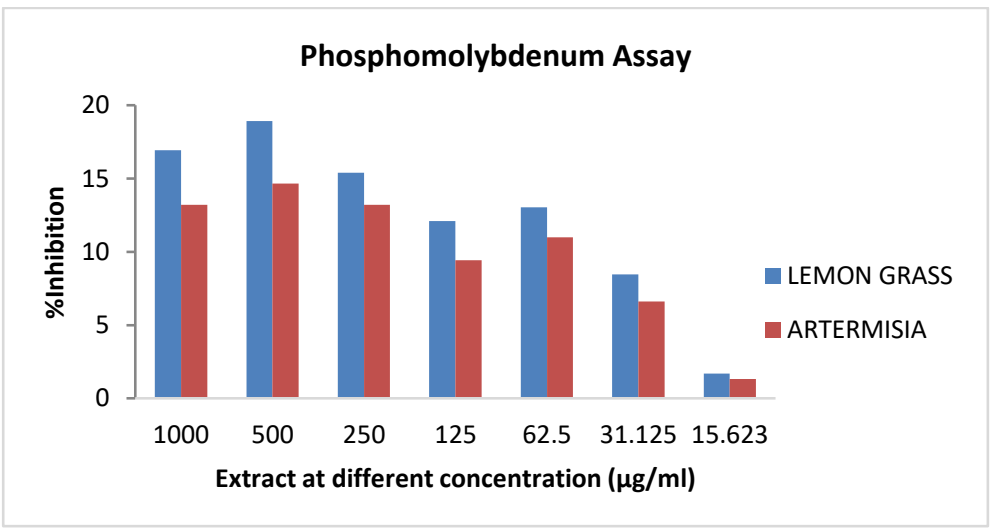

Fig. 1: Inhibition of Phosphomolybdenum in Leaf Extract of Lemongrass and Sweet Wormwood at Different Concentration.

Lemongrass and sweet wormwood show increase in concentration of phosphomolybdenum at increased absorbance. That is, the higher the absorbance, the higher the concentration of phosphomolybdenum. Ascorbic acid was used as standard.

Table 2: DPPH (1,1-Diphenyl-2-Picrylhydrazyl) Assay

\begin{tabular}{llll}
\hline Concentration $(\mu \mathrm{g} / \mathrm{ml})$ & Absorbance for Lemongrass & Absorbance for Artemisia annua & Absorbance for Ascorbic acid \\
\hline 1000 & 81.4392 & 83.2267 & 97.94 \\
500 & 69.5665 & 70.9062 & 97.53 \\
250 & 55.2168 & 52.3241 & 96.74 \\
125 & 37.5444 & 27.3348 & 96.57 \\
62.5 & 25.0142 & 23.1947 & 95.74 \\
31.125 & 19.4812 & 17.9353 & 82.28 \\
15.625 & 17.0398 & 11.2011 & 74.11 \\
\hline
\end{tabular}




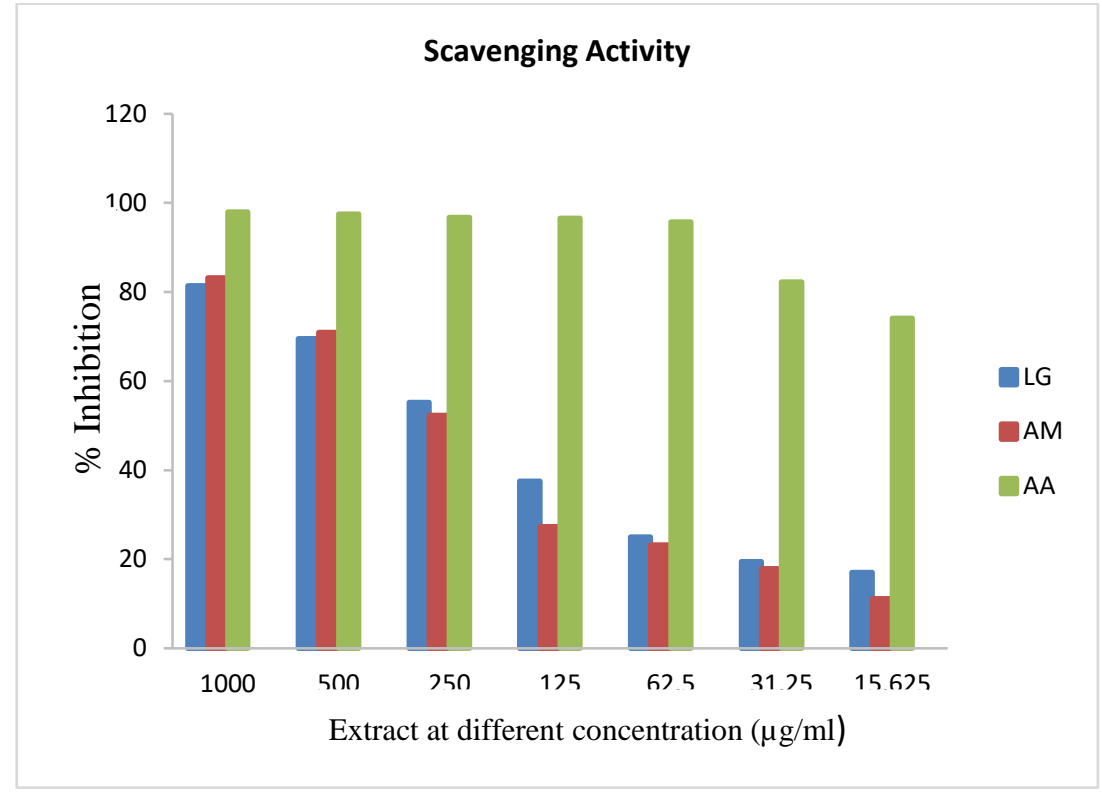

Fig. 2: DPPH Radical Scavenging Activity at Different Concentration of Leaf Extracts of Lemongrass and Sweet Wormwood.

Sweet wormwood and lemongrass have indicated increase in scavenging radical activity when the absorbance increase at all the concentration.

\subsection{Phytochemical component}

Table 3: Qualitative Phytochemical Analysis of Lemon Grass and Sweet Wormwood

\begin{tabular}{lll}
\hline Component & Lemon grass & Sweet wormwood \\
\hline Alkaloids & - & - \\
Flavonoids & + & + \\
Tannin & + & + \\
Cardiac glycoside & + & + \\
Anthraquinones & - & - \\
Carbohydrate & + & + \\
Steroids & + & + \\
Saponins & + & + \\
\hline
\end{tabular}

Key; (+) stand for present and (-) stand for absent.

The result obtained showed the presence of phytochemicals in lemongrass and sweet wormwood such as flavonoid, tannin, steroid, saponins, carbohydrates and cardiac glycoside. However, Anthraquinones and Alkaloids were not found in lemon grass and sweet wormwood.

\subsection{Discussion}

The results of the qualitative phytochemical analysis in lemon grass leaves and sweet wormwood leaves showed carbohydrate, flavonoid, saponins, cardiac glycoside, tannin and steroid were found present. However, anthraquinones and alkaloids were not found in both lemon grass and sweet wormwood. These secondary metabolites were reported to have many biological and therapeutic properties (Vishnu et al., 2013).

The antioxidant activity was determined to be effective through the various assays. The free radical scavenging activity with respect to DPPH(1,1-diphenyl-2-picrylhydrazyl) showed that lemongrass and sweet wormwood indicated increase in scavenging radical activity at increased concentrations. But at $125 \mu \mathrm{g} / \mathrm{ml}$ and $15.625 \mu \mathrm{g} / \mathrm{ml}$ concentration reveal that lemongrass exhibit a higher percentage of inhibition of oxidation than the other specie analyzed. Which also means that lemongrass indicated higher scavenging activity compared to sweet wormwood.

The Higher the DPPH radical scavenging activity could be attributed to higher flavonoids and phenolic content in the samples. Base on the experiment observed, lemongrass has higher content of phenol and flavonoid, and these phytochemicals are responsible for the higher DPPH scavenging activity (Jamuna et al., 2014).

The total antioxidant assay shows the ability of reducing the power of phosphomolybdenum in the leaves extracts at different concentrations. These phosphomolybdenum assay result showed that there was an increase in the absorbance when the concentration increases which was determined in the standard calibration curve.

Lemongrass leaves and Sweet wormwood leaves extract showed an increasing order of magnitude; still the difference in the free radical activity is marginal with reference to increase in concentrations of the plant extract tested. However, a correlative relationship has been reported between the phytochemicals such as tannins, phenol and flavonoids and the free radical scavenging activity and antibacterial activity (Kaur et al., 2010). Tannins and flavonoids have therapeutic uses due to their anti-inflammatory, antifungal, antioxidant and healing properties (Thiago et al., 2008). The higher the inhibition the higher the antioxidant activity.

Antioxidants are believed to play a very important role in the body defense system against reactive oxygen species (ROS), which are the harmful by-products generated during normal cell aerobic respiration (Sulekha et al., 2009).

\subsection{Conclusion}


The findings of the current study have shown that Lemon grass leaves possesses higher Total Phenolic and flavonoid Content than Sweet wormwood leaves which lead to high scavenging activity. However, Lemon grass leaves has expressed higher free radical scavenging effect (i.e., the primary antioxidant activity) as compared to Sweet wormwood leaves.

\section{References}

[1] Yu-Jie Z, Gui-Fang D, Xiang-Rong X, Shan W, Sha L and Hua-Bin L (2013) Chemical components and bioactivities of cape gooseberry (physalis peruwiana). International Journal of Food Nutrition and Safety 3(1): 15-24.

[2] László S, Attila H, Éva S (2005) Presumable protective role of peroxidase and polyphenol oxidase enzymes against freezing stress in peach (Prunus persica L. Batsch). - Acta Bioloca Szegediensis 49(1-2): 121-122.

[3] Lobo V, Patil A, Phatak A and Chandra N (2010) Free radicals, antioxidants and functional foods: Impact on human health. Pharmacognosy Reviews,4,8,118-126. https://doi.org/10.4103/0973-7847.70902.

[4] Miral D, Pawel J (2012) Mechanisms of free radical-induced damage to DNA. Free Radical Research 46(4):382-419. https://doi.org/10.3109/10715762.2011.653969.

[5] Satish B N and Dilipkumar P (2015) Free radicals, natural antioxidants, and their reaction mechanisms. Royal Society of Chemistry 5, 27986-28006. https://doi.org/10.1039/C4RA13315C.

[6] Michael HG (2012) Significance of Dietary Antioxidants for Health. International Journalof Molecular Sciences 13(1): 173-179. https://doi.org/10.3390/ijms13010173.

[7] Azwanida N.N (2015) A Review on the Extraction Methods Use in Medicinal Plants, Principle, Strength and Limitation. Medicinal and Aromatic Plants 4: 2-4. https://doi.org/10.4172/2167-0412.1000196.

[8] Prieto P, Pineda $M$ and Anguiler M (1999) Spectrophotometric quantitation of antioxidant capacity through the formation of a Phosphomolybdenum Complex: Specific Application to the Determination of Vitamin E. Analytical Biochemistry 269:337-341. https://doi.org/10.1006/abio.1999.4019.

[9] Zhu K, Zhou H, and Qian H (2006) Antioxidant and free radical scavenging activities of wheat germ protein hydrolysates (WGPH) prepared with alcalase. Process Biochemistry 41(6):1296-302. https://doi.org/10.1016/j.procbio.2005.12.029.

[10] Vishnu R, Nisha R, Jarmuna S, and Paulsamy S (2013) Quantification of total phenolics and flavonoid and evalution of in vitro antioxidant properties of Methanolic leaf extract of tarenna asitatic an endemic medicinal plant species of Maruthamali hills, western Ghats, Tami Nadu. Journal of Research in plant Science 2(2):196-204.

[11] Jamuna S, Subramaniam P, Krishnamoorthy K (2014) Phytochemical analysis and evaluation of leaf and root parts of the medicinal herb, Hypochaeris radicata L. for in vitro antioxidant activities. Asian Pacific Journal of Tropical Biomedicine 4(Suppl 1): S359-S367. https://doi.org/10.12980/APJTB.4.2014C1030.

[12] Kaur J, Xavier R, Marimuthu, Leng K, Rajasekaran A, Kathiresan S, and Sreeramanan S (2010) Preliminary investigation on the antibacterial activity of mango (Mangifera indica L: Anacardiaceae) seed kernel. Asian Pacific Journal of Tropical Medicine3(9): 707-710. https://doi.org/10.1016/S1995-7645(10)60170-8.

[13] Thiago A, Nelson L, Elba L, andUlysses P (2008) New approach to study medicinal plants with tannins and flavanoids contents from the local knowledge. Journal of Ethnopharmacology; 120: 72-80. https://doi.org/10.1016/i.jep.2008.07.032.

[14] Sulekha M, Satish Y, Sunita Y, and Rajesh K. N (2009) Antioxidants: A Review. Journal of Chemical and Pharmaceutical Research 1 (1):102-104. 